\title{
Evaluación del perfil metabólico lipídico en cerdas suplementadas con Lactobacillus casei durante un ciclo reproductivo
}

\author{
Assessment of the lipid metabolic profile in sows supplemented with Lactobacillus \\ casei during a reproductive cycle
}

\author{
Rafael Suárez ${ }^{1,4}$, Clemencia Fandiño de Rubio³, Iang Rondón-Barragán ${ }^{2,3}$
}

\section{Resumen}

\begin{abstract}
Una microbiota intestinal equilibrada constituye una barrera eficaz contra la colonización de patógenos, además de producir sustratos metabólicos (e.g. vitaminas, enzimas) y estimular el sistema inmunológico de mucosas. La suplementación con probióticos ha demostrado mejorar la digestibilidad en cerdos y servir como inmunoestimulante. El objetivo del presente trabajo fue evaluar el perfil metabólico lipídico en cerdas suplementadas con Lactobacillus casei a través de un ciclo reproductivo. Se emplearon 18 cerdas F1 Landrace $x$ Large White distribuidas completamente al azar en tres grupos: control, T1 suplementado con $10 \times 10^{6}$ UFC (unidades formadoras de colonias/g) de L. casei y T2 suplementado con $10 \times 10^{8} \mathrm{UFC} / \mathrm{g}$ de $L$. casei, con frecuencia de administración semanal por vía oral, durante 180 días, cubriendo un ciclo reproductivo. Se analizaron los metabolitos del perfil lipídico, hemático y proteico de cada hembra en el día del servicio, a los 80 y 113 días de gestación, al primer y décimo día posparto y a los 21 días de la lactancia (destete). En el periparto se encontraron diferencias en triglicéridos y nitrógeno ureico en sangre (BUN), donde T1 y T2 presentaron mayores concentraciones de triglicéridos $(\mathrm{p}<0.05)$ y menores concentraciones de BUN $(\mathrm{p}<0.01)$ que el grupo control. Al momento del destete se presentaron diferencias en las variables triglicéridos y lipoproteína de baja densidad $(\mathrm{p}<0.05)$, donde T1 y T2 fueron menores al control. Las cerdas en fase de gestación y lactancia suplementadas por vía oral con L. casei mostraron mayores niveles de
\end{abstract}

${ }^{1}$ Grupo de Investigación en Genética y Biotecnología de la Reproducción, Facultad de Medicina Veterinaria y Zootecnia, Universidad del Tolima, Ibagué, Tolima, Colombia

${ }^{2}$ Grupo de Investigación en Inmunobiología y Patogénesis, Facultad de Medicina Veterinaria y Zootecnia, Universidad del Tolima, Ibagué, Tolima, Colombia

${ }^{3}$ Grupo de Investigación en Avicultura, Facultad de Medicina Veterinaria y Zootecnia, Universidad del Tolima, Ibagué, Tolima, Colombia

${ }^{4}$ E-mail: rasuarezm@ut.edu.co

Recibido: 28 de febrero de 2018

Aceptado para publicación: 6 de septiembre de 2018 
triglicéridos y colesterol sanguíneos comparados con las hembras no suplementadas. No se encontró efecto de la suplementación sobre la lipoproteína de alta densidad, proteínas totales y albúmina. Estos cambios pueden tener efectos metabólicos benéficos para la cerda; no obstante, se requieren más estudios para dilucidar el papel de la suplementación probiótica sobre el perfil metabólico.

Palabras clave: probiótico; Lactobacillus casei; cerdas; perfil metabólico

\section{Abstract}

A stable microbiota can act as an effective barrier against pathogen colonization besides to the production of metabolic substrates (e.g. vitamins, enzymes) and stimulate the mucosal immunity. Supplementation with probiotics have shown to improve the digestibility in pigs and work as an immunostimulant. The aim of this study was to assess the lipid metabolic profile in sows supplemented with Lactobacillus casei throughout a complete reproductive cycle. Eighteen F1 Landrace x Large White sows were randomly distributed in three experimental groups: control, T1 supplemented with $10 \times 10^{6} \mathrm{CFU}$ (colony forming units)/g of $L$. casei and T2 supplemented with $10 \times 10^{8} \mathrm{CFU} / \mathrm{g}$ of $L$. casei, administered weekly by oral route for 180 days, covering a reproductive cycle. Metabolites from lipid metabolic, hematic and protein profiles were analyzed in each sow at the day of service, 80 -day and 113-day of pregnancy, $1^{\text {st }}$ and $10^{\text {th }}$ day postpartum and at 21 days of lactation (weaning age). At the peripartum period, differences were found in the levels of triglycerides and blood urea nitrogen $(\mathrm{BUN}), \mathrm{T} 1$ and T2 showed higher values of triglycerides $(p<0.05)$ and lower concentration of BUN $(p<0.01)$ than the control group. At weaning time, T1 and T2 showed lower values of triglycerides and low-density lipoprotein $(\mathrm{p}<0.05)$ than control group. Sows in pregnancy and lactation period supplemented with $L$. casei showed higher levels of triglycerides and cholesterol than those without supplementation. In addition, probiotic supplementation did not induce changes in high-density lipoprotein, total protein, and albumin levels. All these changes may have positive metabolic effects for the sows, nevertheless, further studies are required to elucidate the role of the supplementation with probiotics on the metabolic profile.

Key words: probiotic; Lactobacillus casei; sows; metabolic profile

\section{INTRODUCCIÓN}

La microbiota intestinal juega un papel importante en la homeostasis de la fisiología digestiva e inmune del tacto gastrointestinal (TGI), mejorando la absorción de nutrientes, metabolizando restos dietéticos no digeribles mediante la producción de enzimas, creando rutas bioquímicas que permiten la fermentación de hidratos de carbono no digeribles (Ventoso, 2017), síntesis de vitaminas (Gill et al., 2006), exclusión competitiva ocupando los sitios de receptores intestinales, específicamente ocluyendo la unión de bacterias competidoras (Kelly et al., 2005), mediante estimulación de la respuesta inmune de manera no inflamatoria (Gaggìa et al., 2010). La microbiota del TGI del cerdo es compleja, biodiversa y se encuentra en constante interacción simbiótica con el hospedero, con una predominancia de especies anaerobias que superan las $10^{11}-10^{12}$ unidades formadoras de colonias (UFC)/g de heces (Rodríguez, 2009). Dichas poblaciones microbianas varían con la edad del animal (Pajarillo et al., 
2015), ubicación intestinal, factores nutricionales (Heinritz et al., 2016) y ambientales (García et al., 2005; Cesária et al., 2012).

La alteración de las poblaciones bacterianas en las mucosas ha sido relacionada con la aparición de enfermedades gastrointestinales (Chiquieri et al., 2007; Giraldo et al., 2015). La proliferación y fijación de patógenos a la mucosa inducen modificaciones estructurales de las células epiteliales de TGI, con acortamiento de las vellosidades intestinales alterando el transporte y la absorción de nutrientes (Chiquieri et al., 2007). Diversos inmunoestimulantes han sido propuestos como alternativa a los antibióticos (Piñeros et al., 2012), siendo los probióticos uno de los cuales estimulan la inmunidad de la mucosa intestinal y sistémica (Manzano et al., 2012; Ashraf y Shah, 2014; Zhu et al., 2014), favoreciendo además el consumo de alimento y la conversión alimenticia (Naqid et al., 2015).

En porcinos, los probióticos han demostrado estimular el consumo de alimento, facilitando la digestión y absorción de nutrientes, mejorando la producción láctea (Angelis et al., 2006; Myers, 2007; Gaggia et al., 2010; Ross et al., 2010), la resistencia a enfermedades (Rautava, 2007), disminuyendo la actividad tóxica microbiana, inhibiendo patógenos por exclusión competitiva (Matsumoto et al., 2006) y estimulando la restauración de células epiteliales del TGI (Resta-Lenert y Barrett, 2003; Rondón et al., 2008; Reyes y Rodríguez, 2012). Así, es posible que los probióticos puedan tener un efecto sobre el metabolismo proteico y energético, y sobre el estado de la salud en general (Sanz et al., 2004; Ortiz y Reuto, 2007; Quemac, 2014; Reece et al., 2015). El objetivo de la presente investigación fue evaluar el perfil metabólico lipídico y algunas variables hemáticas en cerdas suplementadas con Lactobacillus casei a través de un ciclo reproductivo.

\section{Materiales y Métodos}

\section{Animales Experimentales}

Los experimentos fueron conducidos en la Central Reproductiva Porcigan (Cajamarca, Tolima, Colombia), usando cerdas F1 Large White x Landrace $(n=18)$, clínicamente sanas, con planes sanitarios completos según régimen normal de producción, vacunación a los 10 días posparto contra parvovirus, erisipela y seis serovares de Leptospira (Zoetis, Argentina) y antiparasitarios a los 80 días de gestación (Doramectina). Las cerdas fueron alimentadas con una dieta comercial, criadas bajo las mismas condiciones ambientales, con temperatura promedio de $18{ }^{\circ} \mathrm{C}$ y con edad productiva de tres partos. Todas fueron adaptadas a cada uno de los grupos (tratamientos), un mes previo al inicio del experimento. El estudio fue aprobado por el comité local de ética, siguiendo la normatividad de la Ley 84 de 1989, Resolución 8430 de 1993 para el uso de animales vivos, y se ajusta a los lineamientos del Código de Ética para el ejercicio profesional de la medicina veterinaria, la medicina veterinaria y zootecnia y la zootecnia (Ley 576 de 2000).

\section{Dosis Probióticas}

Lactobacillus casei $\left(\mathrm{ATCC}^{\circledR} 393^{\mathrm{TM}}\right.$ ) fue empleada como cepa probiótica, almacenada a $-20^{\circ} \mathrm{C}$ en caldo De Man, Rogosa y Sharpe (MRS) suplementado con $20 \%$ de glicerol (v/v). Para su uso, las alícuotas de estos cultivos se reactivaron en caldo MRS e incubadas a $37^{\circ} \mathrm{C}$ durante $24 \mathrm{~h}$, y luego sembradas en agar MRS (Oxoid, Alemania) e incubadas a $37^{\circ} \mathrm{C}$ durante $48 \mathrm{~h}$. Las colonias aisladas se transfirieron a caldo MRS (Oxoid, Alemania) e incubaron a $37^{\circ} \mathrm{C}$ hasta que alcanzaron una turbidez similar al tubo 1 en la escala de MacFarland $\left(3 \times 10^{8} \mathrm{UFC} / \mathrm{ml}\right)$, a partir del cual se realizaron diluciones seriadas (1:10) en $\mathrm{NaCl} 0.85 \%$ (w/v) obteniendo las concentraciones de $10 \times 10^{6}$ y $10 \times 10^{8}$ UFC (Colombo et al., 2014). 


\section{Suplementación con $L$. casei}

Para la evaluación del efecto de la suplementación probiótica sobre los parámetros productivos, los sujetos experimentales fueron distribuidos en tres grupos completamente al azar, T0 como grupo control $(n=6), \mathrm{T} 1,(n=6)$ suplementado con $10 \times 10^{6}$ UFC de $L$. casei y T2, $(n=6)$ suplementado con $10 \times 10^{8}$ UFC de L. casei. El inóculo fue administrado vía oral mediante una jeringa dosificadora, en horas de la tarde (18:00), con frecuencia de suministro semanal, durante 180 días, cubriendo más de un ciclo reproductivo completo, incluyendo el proceso de adaptación.

La alimentación durante la gestación hasta el día 85 fue restringida $(1 \mathrm{~kg})$, dos veces por día, de alimento gestación y del día 86 al 114 se suministró $1.5 \mathrm{~kg}$ de alimento de lactancia, dos veces al día. Luego del parto, las cerdas consumieron $1 \mathrm{~kg} /$ día y fueron aumentando de manera gradual hasta alcanzar $6.5 \mathrm{~kg} / \mathrm{hembra} /$ día. El alimento sobrante fue pesado al final del día para tener un registro del consumo real.

\section{Perfil Metabólico}

Se tomaron muestras de sangre mediante venopunción yugular sin anticoagulante y con EDTA-Na como anticoagulante (Clark y Coffer, 2008) en el día del servicio, días 80 y 113 de la gestación, y en los días 1,10 y 21 del posparto, siendo el día 21 el día del destete. Las muestras fueron mantenidas en refrigeración y almacenadas en el Laboratorio de Diagnóstico Veterinario de la Universidad del Tolima (LADIVE) hasta su uso. Las muestras sin anticoagulante se centrifugaron a $600 \mathrm{~g}$ durante 15 minutos y los sueros obtenidos fueron mantenidos a $4{ }^{\circ} \mathrm{C}$.

La química sanguínea para los metabolitos colesterol (CT), triglicéridos (TG), lipoproteínas de alta densidad (HDL), lipoproteínas de baja densidad (LDL), fosfatasa alcalina (ALP), albúmina (ALBU) y proteína total $(\mathrm{PT})$, se determinaron me- diante el equipo de química sanguínea BTS370 Plus $^{\circledR}$ (BioSystems, Barcelona). Las variables hemáticas, recuento de eritrocitos (ERIT), hemoglobina (HB), hematocrito (HTO), recuento leucocitario (LEU) y plaquetas (PLAQ), se leyeron en el equipo de hematología Hema Screen $18^{\circledR}$ (Hospitex Diagnostics, Italia).

Los metabolitos séricos como la glucosa en sangre (GLU), el nitrógeno ureico (BUN) y la creatinina (CREA), se midieron de forma directa mediante el equipo portátil de química sanguínea i-STAT ${ }^{\circledR}$ (Portable Clinical Analyzer Promo), mediante el kit iSTAT CHEM8+.

\section{Análisis Estadístico}

Los datos fueron tabulados y analizados mediante el paquete estadístico SPSS v. 22 para Windows (IBM, EEUU), sometidos a un análisis descriptivo unidimensional y posterior a la validación de los supuestos estadísticos, analizados mediante análisis de varianza, seguido de comparación múltiple de Tukey o Dunnett, como análisis pos hoc, según cada caso. De la misma manera, la prueba de Kruskal-Wallis fue empleada para variables no paramétricas. Para todas las pruebas, $\mathrm{p}<0.05$ fue considerado estadísticamente significativo.

\section{Resultados y Discusión}

Durante el periodo experimental los animales no evidenciaron signos clínicos compatibles con patologías o condiciones clínicas que pudiesen influir en los resultados del perfil metabólico.

Los parámetros hematológicos y bioquímicos son afectados por una variedad de factores, incluyendo la edad, sexo, estado nutricional y de salud, raza, estación y estrés (Douglas y Jane, 2010). Las variables hemáticas fueron evaluadas a través de seis momentos de importancia en el ciclo 
reproductivo de la hembra, con valores para todos los grupos dentro de los parámetros normales según Douglas y Jane, (2010) y Semiadi et al., (2009). Se hallaron diferencias significativas en los niveles de eritrocitos (ERIT) y hemoglobina (HB) en el día 10 posparto, con valores menores en $\mathrm{T} 1$ y $\mathrm{T} 2$ comparados con el grupo control. En el día 1 posparto, los valores de hemoglobina corpuscular media (HCM) y plaquetas (PLAQ) fueron mayores en el grupo control comparados con T2. En el día 80 de gestación las PLAQ fueron mayores en el control comparadas con T2. Las variables volumen corpuscular medio (VCM), concentración media de hemoglobina corpuscular (CMHC) $\mathrm{y}$ recuento de leucocitos (LEU) no presentaron diferencias entre grupos (Cuadros 1 y 2). Los resultados contrastan con Devi y Kim (2014), quienes no hallaron diferencias en los valores de ERIT, LEU, HB y hematocrito (HTO) entre animales suplementados con Lactobacillus sp.

No se encontraron diferencias significativas en las concentraciones de LEU entre tratamientos en las diferentes etapas productivas. Sin embargo, Douglas y Jane (2010), reporta que el número total de LEU se altera durante el parto con neutrofilia, con desplazamiento a la izquierda y linfopenia, pero la proporción de neutrófilos/linfocitos se invierte dentro de las 24 horas siguientes al parto. La caída en los valores de hematocrito en el periparto permaneció dentro de los rangos aceptados como normales para este estado fisiológico con respecto a los valores iniciales (Clark y Coffer, 2008).

La homeostasis de la glucosa es necesaria para responder a las demandas metabólicas del animal (Rodriguez y Caicedo, 2014). En el último tercio de la gestación, la glucosa constituye el principal combustible energético para el crecimiento fetal y la lactogénesis (Mosnier et al., 2010) mientras que en la lactancia las demandas energéticas inducen la disminución de insulina e incrementa la lipolisis de las reservas de grasa (Reece et al., 2015). En un estudio,
Yamano et al. (2006) reportaron que la administración oral de $L$. casei reduce las concentraciones de glucosa en sangre en un modelo murino. Esta disminución se debe probablemente a la inhibición del estímulo simpático del tejido adiposo y de la glándula suprarrenal que disminuyen la secreción de adrenalina y reducen los niveles de glucagón y glucosa en la sangre (Rao, 2007). Sin embargo, aunque los niveles de glucosa estuvieron por fuera de los límites $(148-135 \mathrm{mg} / \mathrm{dl})$ (Bollen et al., 2010; Douglas y Jane, 2010), la glucosa presentó diferencias significativas el día 0 , donde los niveles de T2 fueron mayores al $\mathrm{T} 1 \mathrm{y}$ al control (Cuadro 3).

El nitrógeno ureico sanguíneo (BUN) es el producto final del metabolismo de las proteínas que refleja el metabolismo de los aminoácidos y su utilización (Corbal et al., 2011). El BUN evidenció diferencias a los 113 días de gestación y al primer día posparto donde solo el T2 fue diferente y menor que el grupo control (Cuadro 3), sugiriendo que las cerdas suplementadas tuvieron una disminución de la síntesis e hidratación de la urea en el hígado y posiblemente un aumento de la síntesis de proteínas (Brown y Cline, 1974). Adicionalmente, se ha propuesto que la suplementación con L. casei genera una mejora en la función renal, ya que puede incrementar la tasa de filtración glomerular (Zeuzem et al., 2015). Los hallazgos en este estudio concuerdan con Liu et al. (2015), quienes demostraron valores de BUN menores en animales suplementados con $L$. brevis y con Mandal et al. (2013) cuyos resultados son similares usando Sporosarcina pasteurii.

La creatinina (CREA) es una molécula creada dentro de los músculos esqueléticos como producto de su metabolismo de trabajo, que refleja la función renal y muscular (Randviir y Banks, 2013). La CREA es una molécula importante porque los niveles de concentración en el suero sanguíneo indican un buen funcionamiento renal (Schiffl y Lang, 2012). En el presente estudio se evidenció que la CREA tuvo diferencias al día 0 , donde 
Cuadro 1. Concentración sérica de las variables hemáticas en cerdas suplementadas con Lactobacillus casei a través de un ciclo productivo (Parte I)

\begin{tabular}{|c|c|c|c|c|c|c|}
\hline Variable & Día & Etapa & Control & $\mathrm{T} 1$ & $\mathrm{~T} 2$ & $P$ \\
\hline \multirow{6}{*}{$\begin{array}{c}\text { ERIT } \\
\times 10^{12} / 1\end{array}$} & 0 & Servicio & $6.30 \pm 0.39^{\mathrm{a}}$ & $6.57 \pm 0.40^{\mathrm{a}}$ & $6.32 \pm 0.15^{\mathrm{a}}$ & 0.422 \\
\hline & 80 & Gestante & $5.73 \pm 0.68^{\mathrm{a}}$ & $6.16 \pm 0.51^{\mathrm{a}}$ & $6.43 \pm 0.50^{\mathrm{a}}$ & 0.181 \\
\hline & 113 & Gestante & $5.96 \pm 0.91^{\mathrm{a}}$ & $5.77 \pm 0.48^{\mathrm{a}}$ & $6.03 \pm 0.52^{\mathrm{a}}$ & 0.821 \\
\hline & 1 & Posparto & $5.92 \pm 0.77^{\mathrm{a}}$ & $5.96 \pm 0.40^{\mathrm{a}}$ & $5.44 \pm 0.59^{\mathrm{a}}$ & 0.350 \\
\hline & 10 & Posparto & $6.12 \pm 0.51^{\mathrm{a}}$ & $5.97 \pm 0.28^{\mathrm{ab}}$ & $5.43 \pm 0.28^{b}$ & $0.031^{*}$ \\
\hline & 21 & Destete & $6.03 \pm 0.65^{\mathrm{a}}$ & $5.86 \pm 0.19^{\mathrm{a}}$ & $5.62 \pm 0.20^{\mathrm{a}}$ & 0.303 \\
\hline \multirow{6}{*}{$\begin{array}{l}\mathrm{H} \mid \mathrm{B} \\
\mathrm{g} / \mathrm{dl}\end{array}$} & 0 & Servicio & $12.09 \pm 0.52^{\mathrm{a}}$ & $12.48 \pm 1.51^{\mathrm{a}}$ & $12.18 \pm 0.98^{a}$ & 0.843 \\
\hline & 80 & Gestante & $10.78 \pm 0.81^{\mathrm{a}}$ & $11.84 \pm 1.47^{\mathrm{a}}$ & $12.88 \pm 1.65^{\mathrm{a}}$ & 0.088 \\
\hline & 113 & Gestante & $10.96 \pm 1.40^{\mathrm{a}}$ & $10.35 \pm 1.04^{\mathrm{a}}$ & $10.91 \pm 0.52^{\mathrm{a}}$ & 0.607 \\
\hline & 1 & Posparto & $11.02 \pm 1.37^{\mathrm{a}}$ & $10.65 \pm 0.94^{\mathrm{a}}$ & $9.33 \pm 1.17^{\mathrm{a}}$ & 0.095 \\
\hline & 10 & Posparto & $11.86 \pm 1.30^{\mathrm{a}}$ & $11.12 \pm 0.57^{\mathrm{ab}}$ & $10.21 \pm 0.39^{b}$ & $0.031^{*}$ \\
\hline & 21 & Destete & $11.45 \pm 1.20^{\mathrm{a}}$ & $10.90 \pm 0.53^{\mathrm{a}}$ & $10.49 \pm 0.20^{\mathrm{a}}$ & 0.182 \\
\hline \multirow{6}{*}{$\begin{array}{c}\text { HTO } \\
\%\end{array}$} & 0 & Servicio & $39.98 \pm 2.16^{\mathrm{a}}$ & $40.46 \pm 2.80^{\mathrm{a}}$ & $38.80 \pm 3.17^{\mathrm{a}}$ & 0.658 \\
\hline & 80 & Gestante & $35.18 \pm 3.80^{\mathrm{a}}$ & $38.22 \pm 3.12^{\mathrm{a}}$ & $39.78 \pm 3.90^{\mathrm{a}}$ & 0.167 \\
\hline & 113 & Gestante & $36.30 \pm 3.97^{\mathrm{a}}$ & $35.06 \pm 3.35^{\mathrm{a}}$ & $37.80 \pm 2.71^{\mathrm{a}}$ & 0.463 \\
\hline & 1 & Posparto & $37.28 \pm 5.17^{\mathrm{a}}$ & $37.22 \pm 3.52^{\mathrm{a}}$ & $33.24 \pm 3.11^{\mathrm{a}}$ & 0.233 \\
\hline & 10 & Posparto & $38.34 \pm 2.28^{a}$ & $38.00 \pm 1.72^{a}$ & $34.78 \pm 1.32^{b}$ & $0.017^{*}$ \\
\hline & 21 & Destete & $37.68 \pm 2.98^{\mathrm{a}}$ & $37.48 \pm 1.08^{\mathrm{a}}$ & $34.70 \pm 0.90^{\mathrm{a}}$ & 0.051 \\
\hline \multirow{6}{*}{$\begin{array}{l}\text { LEU } \\
\mathrm{x} 10^{9} / 1\end{array}$} & 0 & Servicio & $23.00 \pm 8.00^{\mathrm{a}}$ & $18.34 \pm 1.27^{\mathrm{a}}$ & $24.00 \pm 6.55^{\mathrm{a}}$ & 0.335 \\
\hline & 80 & Gestante & $17.08 \pm 1.73^{\mathrm{a}}$ & $14.50 \pm 1.86^{\mathrm{a}}$ & $16.62 \pm 2.67^{a}$ & 0.166 \\
\hline & 113 & Gestante & $15.56 \pm 5.19^{a}$ & $16.64 \pm 4.84^{\mathrm{a}}$ & $14.78 \pm 3.45^{\mathrm{a}}$ & 0.813 \\
\hline & 1 & Posparto & $16.84 \pm 2.66^{\mathrm{a}}$ & $16.00 \pm 3.38^{a}$ & $14.84 \pm 6.35^{\mathrm{a}}$ & 0.777 \\
\hline & 10 & Posparto & $15.40 \pm 3.77^{\mathrm{a}}$ & $17.88 \pm 2.65^{\mathrm{a}}$ & $17.54 \pm 3.49^{a}$ & 0.467 \\
\hline & 21 & Destete & $17.00 \pm 5.08^{\mathrm{a}}$ & $13.40 \pm 1.71^{\mathrm{a}}$ & $15.14 \pm 3.00^{\mathrm{a}}$ & 0.311 \\
\hline \multirow{6}{*}{$\begin{array}{l}\text { PLAQ } \\
\times 10^{9} / 1\end{array}$} & 0 & Servicio & $332.00 \pm 108.03^{\mathrm{a}}$ & $304.40 \pm 89.53^{\mathrm{a}}$ & $353.75 \pm 52.18^{\mathrm{a}}$ & 0.713 \\
\hline & 80 & Gestante & $375.60 \pm 50.42^{\mathrm{a}}$ & $256.60 \pm 50.08^{b}$ & $311.60 \pm 25.28^{\mathrm{ab}}$ & $0.004 * *$ \\
\hline & 113 & Gestante & $276.80 \pm 162.66^{a}$ & $217.20 \pm 79.07^{\mathrm{a}}$ & $198.20 \pm 63.82^{\mathrm{a}}$ & 0.522 \\
\hline & 1 & Posparto & $315.60 \pm 81.83^{\mathrm{a}}$ & $268.60 \pm 69.09^{\mathrm{ab}}$ & $157.80 \pm 64.27^{b}$ & $0.013^{*}$ \\
\hline & 10 & Posparto & $326.20 \pm 70.00^{\mathrm{a}}$ & $324.80 \pm 87.16^{\mathrm{a}}$ & $294.00 \pm 54.60^{\mathrm{a}}$ & 0.731 \\
\hline & 21 & Destete & $307.40 \pm 114.71^{\mathrm{a}}$ & $223.20 \pm 31.71^{\mathrm{a}}$ & $258.00 \pm 45.18^{\mathrm{a}}$ & 0.231 \\
\hline
\end{tabular}

ERIT: Eritrocitos; HB: Hemoglobina; HTO: Hematocrito; LEU: Leucocitos; PLAQ: Plaquetas. Letras diferentes dentro de fila denotan diferencias significativas entre tratamientos $\left({ }^{*} p<0.05 ;{ }^{* *} p<0.01\right)$ TO: control; T1 y T2: suplementados con $10 \times 10^{6}$ y $10 \times 10^{8}$ UFC de $L$. casei, respectivamente 
Cuadro 2. Concentración sérica de las variables hemáticas en cerdas suplementadas con Lactobacillus casei a través de un ciclo productivo (Parte II)

\begin{tabular}{cclcccc}
\hline Variable & Día & Etapa & Control & T1 & T2 & $P$ \\
\hline VCM & 0 & Servicio & $62.91 \pm 2.70^{\mathrm{a}}$ & $61.63 \pm 3.31^{\mathrm{a}}$ & $61.37 \pm 4.29^{\mathrm{a}}$ & 0.764 \\
$\mathrm{fl}$ & 80 & Gestante & $61.50 \pm 1.54^{\mathrm{a}}$ & $62.16 \pm 4.65^{\mathrm{a}}$ & $61.83 \pm 2.94^{\mathrm{a}}$ & 0.951 \\
& 113 & Gestante & $61.30 \pm 3.63^{\mathrm{a}}$ & $60.79 \pm 3.04^{\mathrm{a}}$ & $62.81 \pm 1.91^{\mathrm{a}}$ & 0.549 \\
& 1 & Posparto & $62.97 \pm 3.48^{\mathrm{a}}$ & $62.34 \pm 3.15^{\mathrm{a}}$ & $61.24 \pm 1.46^{\mathrm{a}}$ & 0.631 \\
& 10 & Posparto & $62.83 \pm 4.07^{\mathrm{a}}$ & $63.70 \pm 1.98^{\mathrm{a}}$ & $64.08 \pm 2.13^{\mathrm{a}}$ & 0.784 \\
& 21 & Destete & $62.66 \pm 3.61^{\mathrm{a}}$ & $63.98 \pm 1.40^{\mathrm{a}}$ & $61.84 \pm 3.05^{\mathrm{a}}$ & 0.505 \\
$\mathrm{HCM}$ & 0 & Servicio & $19.05 \pm 1.37^{\mathrm{a}}$ & $19.98 \pm 1.78^{\mathrm{a}}$ & $19.27 \pm 1.29^{\mathrm{a}}$ & 0.959 \\
$\mathrm{pg}$ & 80 & Gestante & $18.90 \pm 0.96^{\mathrm{a}}$ & $19.24 \pm 2.07^{\mathrm{a}}$ & $19.98 \pm 1.36^{\mathrm{a}}$ & 0.537 \\
& 113 & Gestante & $18.47 \pm 0.73^{\mathrm{a}}$ & $17.95 \pm 0.90^{\mathrm{a}}$ & $18.17 \pm 0.92^{\mathrm{a}}$ & 0.638 \\
& 1 & Posparto & $18.62 \pm 0.70^{\mathrm{a}}$ & $17.87 \pm 0.77^{\mathrm{ab}}$ & $17.16 \pm 0.83^{\mathrm{b}}$ & $0.035^{*}$ \\
& 10 & Posparto & $19.39 \pm 1.61^{\mathrm{a}}$ & $18.65 \pm 0.95^{\mathrm{a}}$ & $18.84 \pm 1.11^{\mathrm{a}}$ & 0.637 \\
$\mathrm{CMHC}$ & 21 & Destete & $19.06 \pm 2.02^{\mathrm{a}}$ & $18.61 \pm 1.01^{\mathrm{a}}$ & $18.70 \pm 0.87^{\mathrm{a}}$ & 0.865 \\
$\mathrm{mg} / \mathrm{dl}$ & 0 & Servicio & $30.26 \pm 0.95^{\mathrm{a}}$ & $30.76 \pm 1.68^{\mathrm{a}}$ & $31.40 \pm 0.37^{\mathrm{a}}$ & 0.387 \\
& 80 & Gestante & $30.72 \pm 1.11^{\mathrm{a}}$ & $30.94 \pm 2.01^{\mathrm{a}}$ & $32.30 \pm 1.08^{\mathrm{a}}$ & 0.221 \\
& 113 & Gestante & $30.51 \pm 0.72^{\mathrm{a}}$ & $29.52 \pm 0.37^{\mathrm{a}}$ & $28.92 \pm 1.08^{\mathrm{a}}$ & 0.081 \\
& 1 & Posparto & $29.61 \pm 0.70^{\mathrm{a}}$ & $28.65 \pm 0.90^{\mathrm{a}}$ & $28.03 \pm 1.46^{\mathrm{a}}$ & 0.102 \\
& 10 & Posparto & $30.96 \pm 1.80^{\mathrm{a}}$ & $29.30 \pm 0.75^{\mathrm{a}}$ & $29.40 \pm 1.46^{\mathrm{a}}$ & 0.186 \\
& 21 & Destete & $30.37 \pm 1.64^{\mathrm{a}}$ & $29.09 \pm 1.31^{\mathrm{a}}$ & $30.24 \pm 0.45^{\mathrm{a}}$ & 0.238 \\
\hline
\end{tabular}

VCM: Volumen corpuscular medio; HCM: Hemoglobina corpuscular media; CMHC: Concentración media de hemoglobina corpuscular. Letras diferentes dentro de filas denotan diferencias significativas entre tratamientos $\left({ }^{*} p<0.05\right)$

TO: control; T1 y T2: suplementados con $10 \times 10^{6}$ y $10 \times 10^{8}$ UFC de L. casei, respectivamente

$\mathrm{T} 1$ y el control tuvieron valores mayores que T2 (Cuadro 3), lo que indica que las hembras suplementadas con $L$. casei en niveles de $10 \times 10^{8}$ pudieran mostrar una mayor recuperación posdestete, ya que concentraciones altas podría indicar alteraciones en las células musculares (Bradley y Done, 1992) asociadas al tracto reproductivo aún en recuperación posparto (Nogueira et al., 2000). Estos resultados difieren de Lan et al. (2016), quienes no evidenciaron diferencias en los niveles de CREA y BUN al suplementar con L. acidophilus.
Las proteínas totales (PT) séricas se sintetizan en el hígado y su concentración puede reflejar el estado metabólico de la proteína hepática (Douglas y Jane, 2010). En el presente estudio, las concentraciones de PT y albúmina (ALBU) se encontraron dentro de los límites normales para porcinos (Douglas y Jane, 2010; Fox et al., 2015), sin mostrar diferencias entre tratamientos (Cuadro 3); sin embargo, Liu et al. (2015) encontraron diferencias significativas para PT, pero no para ALBU cuando suplementaron cerdos con Lactobacillus brevis. 
Cuadro 3. Concentración sérica de metabolitos sanguíneos en cerdas suplementadas con Lactobacillus casei a través de un ciclo productivo

\begin{tabular}{|c|c|c|c|c|c|c|}
\hline Variable & Día & Etapa & Control & $\mathrm{T} 1$ & $\mathrm{~T} 2$ & $P$ \\
\hline \multirow{6}{*}{$\begin{array}{c}\text { GLUC } \\
\mathrm{mg} / \mathrm{dl}\end{array}$} & 0 & Servicio & $66.40 \pm 5.68^{\mathrm{a}}$ & $74.60 \pm 3.97^{\mathrm{ab}}$ & $81.40 \pm 5.68^{\mathrm{b}}$ & $0.002 * *$ \\
\hline & 80 & Gestante & $75.80 \pm 6.94^{\mathrm{a}}$ & $78.20 \pm 3.27^{\mathrm{a}}$ & $76.80 \pm 4.44^{\mathrm{a}}$ & 0.763 \\
\hline & 113 & Gestante & $71.00 \pm 2.24^{\mathrm{a}}$ & $69.60 \pm 0.89^{\mathrm{a}}$ & $80.00 \pm 7.97^{b}$ & $0.004 * *$ \\
\hline & 1 & Posparto & $80.80 \pm 1.79^{a}$ & $78.40 \pm 3.58^{\mathrm{a}}$ & $77.20 \pm 9.55^{\mathrm{a}}$ & 0.636 \\
\hline & 10 & Posparto & $74.40 \pm 7.67^{\mathrm{a}}$ & $81.80 \pm 3.03^{\mathrm{ab}}$ & $86.80 \pm 8.53^{b}$ & $0.043^{*}$ \\
\hline & 21 & Destete & $78.20 \pm 8.32^{\mathrm{a}}$ & $81.20 \pm 9.68^{\mathrm{a}}$ & $82.00 \pm 5.96^{\mathrm{a}}$ & 0.744 \\
\hline \multirow{6}{*}{$\begin{array}{l}\text { BUN } \\
\mathrm{mg} / \mathrm{dl}\end{array}$} & 0 & Servicio & $13.60 \pm 3.21^{\mathrm{a}}$ & $17.20 \pm 3.96^{\mathrm{a}}$ & $16.20 \pm 2.77^{\mathrm{a}}$ & 0.254 \\
\hline & 80 & Gestante & $27.00 \pm 2.00^{\mathrm{a}}$ & $31.60 \pm 4.34^{\mathrm{a}}$ & $31.00 \pm 2.92^{\mathrm{a}}$ & 0.880 \\
\hline & 113 & Gestante & $18.60 \pm 1.14^{\mathrm{a}}$ & $17.60 \pm 2.19^{\mathrm{ab}}$ & $15.20 \pm 1.64^{b}$ & $0.024 *$ \\
\hline & 1 & Posparto & $22.20 \pm 2.05^{\mathrm{a}}$ & $19.40 \pm 1.52^{\mathrm{ab}}$ & $16.20 \pm 2.68^{b}$ & $0.003 * *$ \\
\hline & 10 & Posparto & $20.00 \pm 3.39^{a}$ & $20.28 \pm 2.28^{\mathrm{a}}$ & $22.80 \pm 1.79^{a}$ & 0.248 \\
\hline & 21 & Destete & $79.40 \pm 1.52^{\mathrm{a}}$ & $19.20 \pm 6.98^{\mathrm{a}}$ & $24.00 \pm 4.42^{\mathrm{a}}$ & 0.248 \\
\hline \multirow{6}{*}{$\begin{array}{l}\text { CREA } \\
\mathrm{mg} / \mathrm{dl}\end{array}$} & 0 & Servicio & $2.62 \pm 0.29^{\mathrm{a}}$ & $2.28 \pm 0.19^{\mathrm{a}}$ & $1.86 \pm 0.09^{b}$ & $<0.001^{* *}$ \\
\hline & 80 & Gestante & $2.5 \pm 0.30^{\mathrm{a}}$ & $2.32 \pm 0.24^{\mathrm{a}}$ & $2.26 \pm 0.27^{\mathrm{a}}$ & 0.376 \\
\hline & 113 & Gestante & $2.40 \pm 0.07^{\mathrm{a}}$ & $2.56 \pm 0.21^{\mathrm{a}}$ & $2.28 \pm 0.49^{\mathrm{a}}$ & 0.390 \\
\hline & 1 & Posparto & $2.46 \pm 0.13^{\mathrm{a}}$ & $2.44 \pm 0.09^{\mathrm{a}}$ & $2.36 \pm 0.34^{\mathrm{a}}$ & 0.745 \\
\hline & 10 & Posparto & $2.42 \pm 0.08^{\mathrm{a}}$ & $2.64 \pm 0.21^{\mathrm{a}}$ & $2.70 \pm 0.19^{\mathrm{a}}$ & 0.052 \\
\hline & 21 & Destete & $2.30 \pm 0.35^{\mathrm{a}}$ & $2.42 \pm 0.49^{\mathrm{a}}$ & $2.18 \pm 0.24^{\mathrm{a}}$ & 0.606 \\
\hline \multirow{6}{*}{$\begin{array}{l}\mathrm{PT} \\
\mathrm{g} / \mathrm{dl}\end{array}$} & 0 & Servicio & $7.94 \pm 0.35^{\mathrm{a}}$ & $7.62 \pm 0.42^{\mathrm{a}}$ & $7.97 \pm 0.47^{\mathrm{a}}$ & 0.356 \\
\hline & 80 & Gestante & $7.90 \pm 0.24^{\mathrm{a}}$ & $8.01 \pm 0.77^{\mathrm{a}}$ & $8.07 \pm 0.73^{\mathrm{a}}$ & 0.916 \\
\hline & 113 & Gestante & $8.07 \pm 0.53^{\mathrm{a}}$ & $7.89 \pm 0.66^{\mathrm{a}}$ & $8.28 \pm 0.42^{\mathrm{a}}$ & 0.549 \\
\hline & 1 & Posparto & $7.70 \pm 0.57^{\mathrm{a}}$ & $7.21 \pm 0.28^{\mathrm{a}}$ & $7.73 \pm 0.64^{\mathrm{a}}$ & 0.248 \\
\hline & 10 & Posparto & $8.02 \pm 0.61^{\mathrm{a}}$ & $6.99 \pm 0.50^{\mathrm{a}}$ & $7.35 \pm 0.71^{\mathrm{a}}$ & 0.058 \\
\hline & 21 & Destete & $7.89 \pm 0.55^{\mathrm{a}}$ & $7.36 \pm 0.31^{\mathrm{a}}$ & $7.87 \pm 0.33^{\mathrm{a}}$ & 0.110 \\
\hline \multirow{6}{*}{$\begin{array}{c}\text { ALBU } \\
\text { g/dl }\end{array}$} & 0 & Servicio & $3.51 \pm 0.52^{\mathrm{a}}$ & $3.48 \pm 0.17^{\mathrm{a}}$ & $3.91 \pm 0.20^{\mathrm{a}}$ & 0.117 \\
\hline & 80 & Gestante & $4.27 \pm 0.55^{\mathrm{a}}$ & $4.72 \pm 0.26^{\mathrm{a}}$ & $4.71 \pm 0.23^{\mathrm{a}}$ & 0.143 \\
\hline & 113 & Gestante & $4.40 \pm 0.07^{\mathrm{a}}$ & $4.36 \pm 0.22^{\mathrm{a}}$ & $4.61 \pm 0.19^{\mathrm{a}}$ & 0.095 \\
\hline & 1 & Posparto & $3.53 \pm 0.14^{\mathrm{a}}$ & $3.48 \pm 0.15^{\mathrm{a}}$ & $3.52 \pm 0.27^{\mathrm{a}}$ & 0.903 \\
\hline & 10 & Posparto & $3.57 \pm 0.41^{\mathrm{a}}$ & $3.21 \pm 0.26^{\mathrm{a}}$ & $3.50 \pm 0.20^{\mathrm{a}}$ & 0.174 \\
\hline & 21 & Destete & $3.47 \pm 0.13^{\mathrm{a}}$ & $3.43 \pm 0.19^{\mathrm{a}}$ & $3.54 \pm 0.24^{\mathrm{a}}$ & 0.650 \\
\hline
\end{tabular}

GLU: Glucosa; BUN: Nitrógeno ureico sanguíneo; CREA: Creatinina; PT: Proteínas totales; ALBU: Albúmina. Letras diferentes dentro de filas denotan diferencias significativas entre tratamientos $\left({ }^{*} p<0.05 ; * * p<0.01\right)$

TO: control; T1 y T2: suplementados con $10 \times 10^{6}$ y $10 \times 10^{8}$ UFC de L. casei, respectivamente 
Cuadro 4. Concentración sérica del perfil lipídico en cerdas suplementadas con Lactobacillus casei a través de un ciclo productivo

\begin{tabular}{|c|c|c|c|c|c|c|}
\hline Variable & Día & Etapa & Control & $\mathrm{T} 1$ & $\mathrm{~T} 2$ & $P$ \\
\hline \multirow{6}{*}{$\begin{array}{c}\mathrm{CT} \\
\mathrm{mg} / \mathrm{dl}\end{array}$} & 0 & Servicio & $79.60 \pm 14.50 \mathrm{a}$ & $69.00 \pm 22.63^{\mathrm{a}}$ & $80.00 \pm 19.65^{\mathrm{a}}$ & 0.604 \\
\hline & 80 & Gestante & $83.40 \pm 6.02^{\mathrm{a}}$ & $86.80 \pm 9.18^{\mathrm{a}}$ & $100.60 \pm 4.16^{\mathrm{b}}$ & $0.003 * *$ \\
\hline & 113 & Gestante & $106.80 \pm 2.05^{\mathrm{a}}$ & $116.00 \pm 7.38^{a}$ & $126.40 \pm 6.23^{b}$ & $0.003 * *$ \\
\hline & 1 & Posparto & $71.20 \pm 14.46^{\mathrm{a}}$ & $69.60 \pm 8.23^{\mathrm{a}}$ & $83.60 \pm 7.54^{\mathrm{a}}$ & 0.112 \\
\hline & 10 & Posparto & $75.00 \pm 7.65^{\mathrm{a}}$ & $76.40 \pm 9.89^{\mathrm{a}}$ & $82.60 \pm 5.27^{\mathrm{a}}$ & 0.300 \\
\hline & 21 & Destete & $79.80 \pm 7.73^{\mathrm{a}}$ & $78.80 \pm 6.02^{\mathrm{a}}$ & $72.40 \pm 12.54^{a}$ & 0.412 \\
\hline \multirow{6}{*}{$\begin{array}{c}\mathrm{TG} \\
\mathrm{mg} / \mathrm{dl}\end{array}$} & 0 & Servicio & $75.20 \pm 13.14^{\mathrm{a}}$ & $69.20 \pm 18.38^{\mathrm{a}}$ & $67.40 \pm 10.69^{a}$ & 0.679 \\
\hline & 80 & Gestante & $73.60 \pm 9.21^{\mathrm{a}}$ & $74.60 \pm 20.46^{\mathrm{a}}$ & $87.20 \pm 5.17^{\mathrm{a}}$ & 0.237 \\
\hline & 113 & Gestante & $87.60 \pm 6.11^{\mathrm{a}}$ & $93.40 \pm 4.16^{\mathrm{ab}}$ & $97.00 \pm 4.74^{b}$ & $0.037 *$ \\
\hline & 1 & Posparto & $58.58 \pm 8.53^{\mathrm{a}}$ & $72.40 \pm 11.67^{\mathrm{b}}$ & $73.80 \pm 5.76^{\mathrm{b}}$ & $0.040 *$ \\
\hline & 10 & Posparto & $53.00 \pm 14.70^{\mathrm{a}}$ & $58.80 \pm 32.51^{\mathrm{a}}$ & $69.80 \pm 22.34^{\mathrm{a}}$ & 0.556 \\
\hline & 21 & Destete & $87.20 \pm 7.63^{\mathrm{a}}$ & $79.20 \pm 8.67^{\mathrm{ab}}$ & $70.80 \pm 5.97^{b}$ & $0.016^{*}$ \\
\hline \multirow{6}{*}{$\begin{array}{l}\mathrm{HDL} \\
\mathrm{mg} / \mathrm{dl}\end{array}$} & 0 & Servicio & $39.40 \pm 17.20^{\mathrm{a}}$ & $36.20 \pm 14.45^{\mathrm{a}}$ & $256.80 \pm 5.54^{\mathrm{a}}$ & 0.318 \\
\hline & 80 & Gestante & $40.80 \pm 13.81^{\mathrm{a}}$ & $54.40 \pm 30.75^{\mathrm{a}}$ & $40.60 \pm 13.22^{\mathrm{a}}$ & 0.508 \\
\hline & 113 & Gestante & $32.80 \pm 6.61^{\mathrm{a}}$ & $35.40 \pm 19.32^{\mathrm{a}}$ & $47.60 \pm 2.97^{\mathrm{a}}$ & 0.132 \\
\hline & 1 & Posparto & $34.20 \pm 12.68^{a}$ & $32.20 \pm 16.28^{a}$ & $24.60 \pm 10.64^{\mathrm{a}}$ & 0.510 \\
\hline & 10 & Posparto & $34.40 \pm 21.28^{\mathrm{a}}$ & $24.20 \pm 2.49^{\mathrm{a}}$ & $45.00 \pm 13.55^{\mathrm{a}}$ & 0.122 \\
\hline & 21 & Destete & $40.40 \pm 13.39^{\mathrm{a}}$ & $49.80 \pm 11.43^{\mathrm{a}}$ & $40.40 \pm 13.69^{\mathrm{a}}$ & 0.437 \\
\hline \multirow{6}{*}{$\begin{array}{l}\mathrm{LDL} \\
\mathrm{mg} / \mathrm{dl}\end{array}$} & 0 & Servicio & $14.40 \pm 4.34^{\mathrm{a}}$ & $15.40 \pm 3.29^{\mathrm{a}}$ & $15.60 \pm 2.88^{\mathrm{a}}$ & 0.851 \\
\hline & 80 & Gestante & $20.80 \pm 6.18^{\mathrm{a}}$ & $22.60 \pm 9.45^{\mathrm{a}}$ & $17.80 \pm 3.96^{\mathrm{a}}$ & 0.556 \\
\hline & 113 & Gestante & $16.20 \pm 5.81^{\mathrm{a}}$ & $18.00 \pm 9.38^{\mathrm{a}}$ & $22.00 \pm 9.19^{\mathrm{a}}$ & 0.544 \\
\hline & 1 & Posparto & $22.40 \pm 9.56^{\mathrm{a}}$ & $23.20 \pm 7.19^{\mathrm{a}}$ & $24.00 \pm 5.34^{\mathrm{a}}$ & 0.946 \\
\hline & 10 & Posparto & $14.20 \pm 2.59^{\mathrm{a}}$ & $15.80 \pm 3.83^{\mathrm{a}}$ & $18.80 \pm 5.81^{\mathrm{a}}$ & 0.265 \\
\hline & 21 & Destete & $26.80 \pm 5.50^{\mathrm{a}}$ & $14.80 \pm 3.77^{b}$ & $21.00 \pm 6.40^{\mathrm{ab}}$ & $0.013 *$ \\
\hline
\end{tabular}

CT: Colesterol; TG: Triglicéridos; HDL: Lipoproteína de alta densidad; LDL: Lipoproteína de baja densidad. Letras diferentes dentro de filas denotan diferencias significativas entre tratamientos $\left({ }^{*} \mathrm{p}<0.05 ; * * \mathrm{p}<0.01\right)$

T0: control; T1 y T2: suplementados con $10 \times 10^{6}$ y $10 \times 10^{8}$ UFC de L. casei, respectivamente

En el presente estudio las cerdas suplementadas con L. casei durante un ciclo productivo evidenciaron niveles séricos de CT mayores que el grupo control durante la gestación (días 80 y 113; $<<0.05$ ). Sin embargo, el incremento en los niveles de CT estuvieron dentro de los límites normales (50-140 $\mathrm{mg} / \mathrm{dl}$ ) reportados para la especie (Bollen et al., 2010; Reece et al., 2015). Estos resulta- dos contrastan con lo reportado en la literatura donde el consumo de probióticos, principalmente Lactobacillus y Bifidobacterium, genera una disminución de los niveles de CT y lipoproteínas de baja densidad (LDL), así como un aumento en los niveles de lipoproteínas de alta densidad (HDL) (Nguyen et al., 2007; Yoo et al., 2007; Sadrzadeh et al., 2010). En este sentido, Aragón (2012) 
usando L. fermentum como probiótico, demostró que influencia el metabolismo catabólico del colesterol mediante la producción de la enzima hidrolasa de sales biliares (BSH), siendo las sales biliares el producto final de esta degradación, coincidiendo con lo reportado con L. reuteri (De Smet et al., 1998), L. plantarum y L. animalis (De Smet et al., 1995), formando nuevas sales biliares (Martoni et al., 2008), influenciando un mayor metabolismo y reducción de colesterol sérico (Du Toit et al., 1998).

La disminución del CT sérico ha sido atribuida a la capacidad de los probióticos de suprimir la reabsorción de ácidos biliares en la circulación enterohepática y aumentar la excreción de esteroides acídicos en heces (Ramasamy et al., 2010; Usman y Hosono, 2000).

Se ha descrito la disminución de la actividad de la HMG-CoA (3-hidroxi-3-metilglutaril-CoA) reductasa hepática, la cual participa en la síntesis endógena de CT (Sungsso y Finocchiaro, 2010) y la capacidad de los probióticos de quelar el CT en el intestino delgado (Kimoto et al., 2002), o su capacidad de convertir el CT a coprostanol a nivel intestinal para ser excretado directamente en las heces, permitiendo por un proceso de homeostasis la reducción del CT sanguíneo (Kimoto et al., 2002). Sin embargo, se debe considerar el anabolismo gestacional, en el cual una cerda preñada toma más ventaja de los alimentos que una cerda vacía, consiguiendo ganar peso durante la gestación y guardar reservas de energía y proteína para la fase de lactación (Lázaro, 2005), lo cual puede explicar las variaciones observadas en el presente estudio.

En la Figura 1 se muestra la dinámica de las concentraciones séricas de los metabolitos lipídicos en cerdas a través de un ciclo productivo. Se evidenció un incremento continuo de las concentraciones séricas de CT (Figura 1A) y triglicéridos (TG) (Figura 1B) desde el servicio hasta el día 113 de gestación, para luego disminuir al primer día posparto; sin embargo, a partir de este momento la variable CT empieza a incrementar en $\mathrm{T} 1$ y en el control hasta el destete, comparado con el T2 donde este decrece desde el día 113 de gestación hasta el destete. Este comportamiento es similar a lo descrito por Aguilar et al. (2015), quienes reportan un aumento progresivo en los TG hasta el momento del parto.

Los TG en los tres grupos evaluados decrecen desde el parto hasta el día 10 posparto coincidiendo con los resultados de Mosnier et al. (2010) donde los niveles de TG disminuyeron en el día 1 del posparto, para luego mostrar un incremento hasta el día del destete. Adicionalmente, en este estudio se evidenció que los niveles de TG y CT en T2 mostraron valores mayores comparados con $\mathrm{T} 1$ en los días 80 y 113 de gestación y en los días 1 y 10 postparto. También se evidenció que los tres grupos presentaron un incremento de los TG y el CT desde el día 80 de gestación hasta un día antes del parto, siendo esto probable ya que mediante circulación materno fetal, el hígado del feto puede sintetizar TG a partir de los ácidos grasos de la madre, y trasportarlos al flujo sanguíneo materno (Mota et al., 2011).

Las concentraciones séricas de TG fueron afectadas por el suministro del probiótico L. casei. Los valores de TG fueron mayores en el $\mathrm{T} 2$ con respecto al control a los 113 días de gestación, el día uno del posparto y el día del destete. Sin embargo, el valor de T1 fue similar al del control en el día 113 de gestación y que T2 en el día del destete. Según Mosnier et al. (2010), las cerdas en el último tercio de la gestación y al inicio de la lactancia presentan una movilización y disminución de los TG séricos por efecto del crecimiento fetal y desarrollo de la glándula mamaria (producción de calostro) (Quiniou et al., 2008; Aguilar et al., 2015), proceso estimulado por hormonas esteroideas y peptídicas como progesterona, estrógenos, oxitocina y prolactina, entre otras (Devillers et al., 2004). Sin embargo, las tendencias actuales de producir hembras con bajas reservas de grasa al 
A
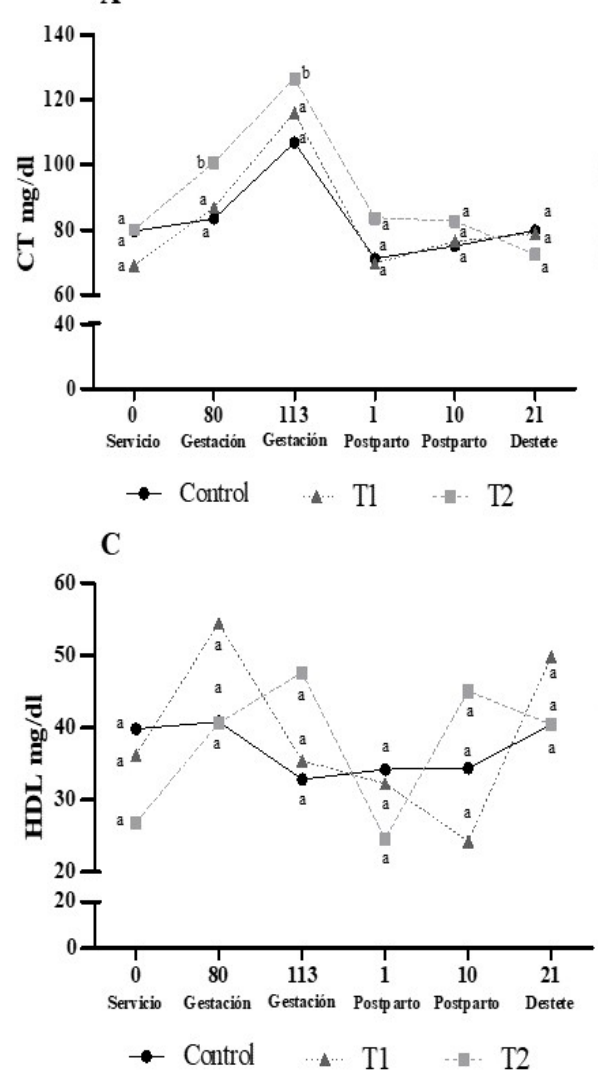

B
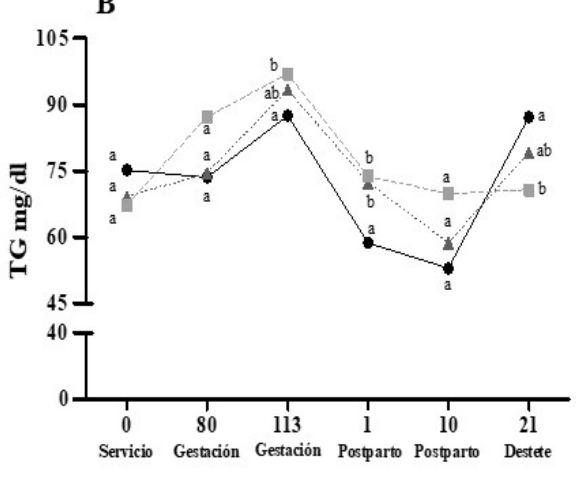

$\rightarrow$ Control a $\quad \mathrm{T} 1 \quad-\mathrm{T} 2$

D

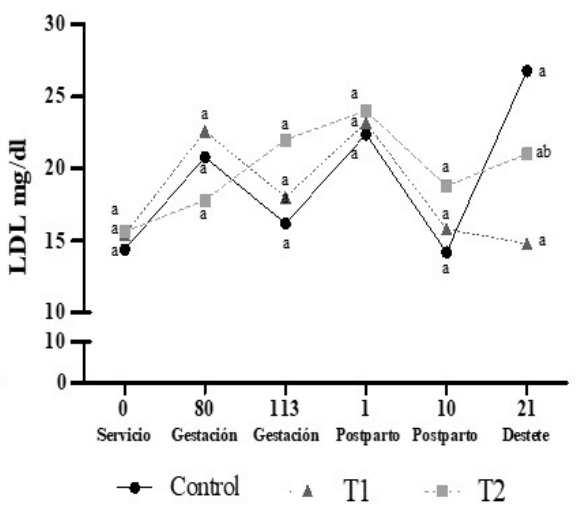

Figura 1. Dinámica de los metabolitos lipídicos en cerdas a través de un ciclo productivo suplementadas con Lactobacillus casei. A) Colesterol, CT; B) Triglicéridos, TG; C) Lipoproteína de alta densidad, HDL; D) Lipoproteína de baja densidad, LDL. T0: control; T1 y T2: suplementados con $10 \times 10^{6}$ y $10 \times 10^{8}$ UFC de $L$. casei, respectivamente

parto y las altas demandas energéticas durante la lactancia deben estar acompañadas de un consumo adecuado de alimento que cubra sus requerimientos nutricionales (Eissen et al., 2000).

La HDL incrementó su concentración en los tres grupos entre el día del servicio y el día 80 de la gestación (Figura 1C), probablemente por el anabolismo gestacional (Lázaro, 2005) continuando con este incremento el T2 hasta el día 113 de gestación, para luego decrecer en el parto y volver a incrementar hasta el día 10 posparto, en comparación con el grupo T1 que decreció constantemente hasta el día 10 posparto, y con el control mostrando un incremento constante desde el día 113 de gestación hasta el día del destete. Este comportamiento puede deberse al aumento de consumo en la lactancia que provoca un aumento del flujo sanguíneo al hígado, induciendo un mayor catabolismo y, por ende, mayores concentraciones en sangre de algunos metabolitos (Carrión y Mendel, 2001). El catabolismo de las HDL es regulado mediante su uso, trasportando TG y mediante el aumento de la actividad de la lipasa hepática, dando un incremento de la eliminación de las partículas HDL y una reducción del nivel total de estas en la sangre circulante (Ariel, 2013). 
Según Bauer (1997), los patrones del metabolismo lipídico están clasificados según la relación HDL:LDL, donde el patrón para los cerdos es LDL $>$ HDL, en la cual el CT es trasportado por LDL en mayor proporción (Osorio, 2013). Esto difiere de lo hallado en el presente estudio, donde los valores de HDL fueron mayores que los LDL (Figuras $1 \mathrm{C} \mathrm{y}$ 1D), lo cual coincide con Ferraro et al. (2004). Es de destacar que los niveles de HDL no mostraron diferencias significativas entre tratamientos, mientras que LDL mostró valores menores en $\mathrm{T} 1$ con respecto al control en el día del destete (Cuadro 4).

La LDL en el T2 se incrementó desde el servicio hasta el primer día posparto, probablemente por el anabolismo gestacional, (Lázaro, 2005), para luego decrecer hasta el día 10 posparto, posiblemente debido al catabolismo de la lactancia (Carrión y Mendel, 2001). Contrario a esto, en el T1 y el grupo control los niveles de LDL decrecieron desde el día 80 hasta el día 113 de gestación. En todos los grupos experimentales los niveles de LDL se incrementaron desde el primer día posparto hasta el día 10 posparto (Figura 1). Coppo et al. (2003) reportan que las concentraciones de LDL aumentan rápidamente al consumir dietas altas en grasas, siendo esta la razón por la cual se agrupa dentro del patrón LDL (Cosentino et al., 2015), pero es de considerar que las cerdas del presente estudio presentaron mayores niveles de HDL, lo cual puede deberse al muestreo en periodo de ayuno en el cual los niveles de LDL no estuvieran lo suficientemente altos en circulación. Adicionalmente, las hembras en gestación tardía, por efecto de los estrógenos y la activación de la resistencia insulínica presentan mayor actividad lipolítica del tejido adiposo, logrando aumentar la HDL trasportadora de TG (Herrera, 2002; Duque et al., 2013). Otros estudios reportan que las LDL están protegidas por antioxidantes, pero bajo condiciones de estrés (gestación-parto-lactancia), estas pueden ser peroxidasas, a diferencia de la HDL que contiene más partículas pro-oxidantes, por lo cual se da la condición de HDL incrementada y LDL reducida (Czech et al., 2009).

\section{Conclusiones}

- El uso de L. casei como suplemento nutricional en cerdas indujo cambios favorables en los parámetros metabólicos en la gestación y lactancia, por lo cual se vislumbra como una alternativa de mejora en los parámetros productivos y remplazo de antibióticos promotores de crecimiento en la producción porcina.

- La suplementación con el probiótico en las cerdas por vía oral en fase de gestación y lactancia generó mayores niveles de concentración séricos de triglicéridos y colesterol comparados con las hembras no suplementadas.

- No se encontró efecto de la suplementación de $L$. casei sobre la lipoproteína de alta densidad, proteínas totales y albúmina.

\section{Literatura CitTada}

1. Aguilar MJ, Baena L, Sánchez A, Guisado R, Hermoso E, Mur N, Capel $M$. 2015. Nivel de triglicéridos como factor de riesgo durante el embarazo; modelado biológico; revisión sistemática. Nutr Hosp 32: 517-527. doi: 10.3305/ nh.2015.32.2.9215

2. Akoglu B, Loytved A, Nuiding $\mathrm{H}$, Zeuzem S, Faus D. 2015. Probiotic Lactobacillus casei Shirota improves kidney function, inflammation and bowel movements in hospitalized patients with acute gastroenteritis. A prospective study. J Funct Foods 17: 305-313. doi: 10.1016/j.jff.2015.05.021

3. Aragón S. 2012. Evaluación bioquímica y molecular de la capacidad hipocolesterolémica de bacterias ácido lácticas con potencial probiótico. Tesis de Maestría. Bogotá, Colombia: Univ. de la Sabana. 109 p.

4. Ariel F. 2013. Metabolismo de lípidos y disfunción endotelial en pacientes diabéticos tipo 2 tratados con insulina o 
hipoglucemiantes orales. Tesis de Doctorado. Argentina: Univ. Nacional de la Plata. $127 \mathrm{p}$.

5. Ashraf R, Shah NP. P. 2014. Immune system stimulation by probiotic by probiotic microorganisms. Crit Rev Food Sci 54: 938-956. doi: 10.1080/ 10408398.2011.619671

6. Bauer JE. 1997. Metabolismo comparado de lípidos y lipoproteínas. Pet's Ciencia 13: 362-376.

7. Bollen P, Hansen A, Olsen A. 2010. The laboratory swine. $2^{\text {nd }}$ ed. London: CRC Press. 138 p.

8. Bradley R, Done JT. 1992. Sistemas nerviosos y musculares. En: Enfermedad porcina. Ames USA: Iowa State University. p 62-58.

9. Brown JA, Cline TR. 1974. Urea excretion in pigs: an indicator of quality and amino acid requirements. J Nutr 104: 542-545. doi: 10.1093/jn/104.5.542

10. Carrión D, Mendel P. 2001. Interacción nutrición reproducción en el ganado porcino. En: Memorias XVII Curso de Especialización FEDNA. España.

11. Chiquieri J, Nery H, Cavalho E, Costa A. 2007. Bioquímica sangüínea e altura das vilosidades intestinais de suínos alimentados com adição de probiótico, prebiótico e antibiótico. Rev Bras Saúde Prod Animal 8: 97-104.

12. Clark SG, Coffer N. 2008. Normal hematology and hematologic disorders in potbellied pigs. Vet Clin North Am Exot Anim Pract 11: 569-582. doi: 10.1016/ j.cvex.2008.03.003

13. Colombo $M$, de Oliveira $A E$, de Carvalho AF, Nero LA. 2014. Development of an alternative culture medium for the selective enumeration of Lactobacillus casei in fermented milk. Food Microbiol 39: 89-95. doi: 10.1016/ j.fm.2013.11.008

14. Coppo NB, Coppo JA, Lazarte MA. 2003. Intervalos de confianza para colesterol ligado a lipoproteínas de alta y baja densidad en suero de bovinos, equinos, porcinos y caninos. Rev Vet 14: 3-10.
15. Cosentino M, Marino F, Maestroni GJ. 2015. Sympathoadrenergic modulation of hematopoiesis: a review of available evidence and of therapeutic perspectives. Frontier Cellular Neurosci 9: 302. doi: 10.3389/fncel.2015.00302

16. Czech A, Mokrzycka A, Grela ER, Pejsak Z. 2009. Influence of mannanoligosaccharides additive to sows diets on blood parameters of sows and their piglets. B Vet I Pulawy 57: 89-95.

17. De Angelis M, Siragusa S, Berloco M, Caputo L, Settanni L, Alfonsi G, Amerio M, et al. 2006. Selection of potential probiotic lactobacilli from pig feces to be used as additives in pelleted feeding. Res Microbiol 157: 792-801. doi: 10.1016/j.resmic.2006.05.003

18. De Smet I, Van Hoorde L, Vande Woestyne M, Christiaens H, Verstraete W. 1995. Significance of bile salt hydrolytic activities of lactobacilli. J Appl Bacteriol 79: 292-301. doi: 10.1111/ j.1365-2672.1995.tb03140.x

19. De Smet ID, de Boever PD, Verstraete W. 1998. Cholesterol lowering in pigs through enhanced bacterial bile salt hydrolase activity. Brit J Nutr 32: 185194. doi: 10.1079/BJN19980030

20. de Souza TCR, Landin GM, Garcia KE, Barreyro AA, Barron AM. 2012. Nutritional changes in piglets and morphophysiologic development of their digestive tract. Vet México 43: 155-173.

21. Devi SM, Kim IH. 2014. Effect of medium chain fatty acids (MCFA) and probiotic (Enterococcus faecium) supplementation on the growth performance, digestibility and blood profiles in weanling pigs. Veterinarni Med 11: 527535.

22. Devillers N, Farmer C, Mounier A, Le dividich J, Prunier A. 2004. Hormones, IgG and lactose changes around parturition in plasma, and colostrum or saliva of multiparous sows. Reprod Nutr Dev 44: 381-396. doi: 10.1051/ rnd:2004043 
23. Douglas J, Jane W. 2010. Veterinary hematology. $6^{\text {th }}$ ed. USA: WileyBlackwell. $1322 \mathrm{p}$.

24. Du Toit M, Franz C, Dicks L, Schillinger $U$, Haberer $P$, Warlies $B$, Ahrens F, et al. 1998. Characterisation and selection of probiotic lactobacilli for a preliminary minipig feeding trial and their effect on serum cholesterol levels, faeces $\mathrm{pH}$ and faeces moisture content. Int J Food Microbiol 40: 93-104. doi: 10.1016/S0168-1605(98)00024-5

25. Duque P, Romulo G, López A. 2013. Evaluación del perfil metabólico lipídico en cerdas gestantes y su relación con la nutrición fetal. Rev MVZ Cordoba 18: 3543-3549.

26. Eissen JJ, Kanis E, Kemp B. 2000. Sow factors affecting voluntary feed intake during lactation. Livest Prod Sci 64: 147-165. doi: 10.1016/S0301-6226(99)00153-0

27. Ferraro S, Saballo A, Márquez A, López A. 2004. Determinación del perfil metabólico en cerdas adultas Landrace-LargeWhite en periodo de periparto. Gaceta Cienc Vet 9: 63-68.

28. Fox J, Anderson L, Tto G, Pritchett K, Mark $W .2015$. Laboratory animal medicine. $3^{\text {rd }}$ ed. USA: Academic Press. $p$ 1746.

29. Gaggìa F, Mattarelli P, Biavati B. 2010. Probiotics and prebiotics in animal feeding for safe food production. Int J Food Microbiol 141(Suppl 1): 15-28. doi: 10.1016/j.ijfoodmicro.2010.02.03

30. García Y, García Y, López A, Boucourt R. 2005. Probióticos: una alternativa para mejorar el comportamiento animal. Rev Cubana Cienc Agríc 39: 129-140.

31. Gill S, Pop M, Deboy R, Eckburg P, Turnbaugh P, Samuel B, Gordon J, et al. 2006. Metagenomic analysis of the human distal gut microbiome. Science 312: 1355-1359. doi: 10.1126/science.1124234

32. Giraldo-Carmona J, Narváez-Solarte W, Díaz-López E. 2015. Probiotics in swine: contradictory results. Biosalud 14: 81-90. doi: 10.17151/biosa.2015.14.1.9
33. Heinritz SN, Weiss E, Eklund M, Aumiller T, Louis S. 2016. Intestinal microbiota and microbial metabolites are changed in a pig model fed a high-fat/ low-fiber or a low-fat/high-fiber diet. Plos One 11: e0154329. doi: 10.1371/journal.pone. 0154329

34. Herrera E. 2002. Implications of dietary fatty acids during pregnancy on placental, fetal and postnatal development. Placenta 23(Suppl A): 9-19. doi: 10.1053/plac.2002.0771

35. Hosono A, Usman J. 2000. Effect of administration of Lactobacillus gasseri on serum lipids and fecal steroids in hypercholesterolemic rats. J Dairy Sci 83: 1705-1711. doi: 10.3168/jds.S00220302(00)75039-9

36. Kelly D, Conway S, Aminov R. 2005. Commensal gut bacteria: mechanisms of immune modulation. Trends Immunol 26: 326-333. doi: 10.1016/j.it.2005.04.008

37. Kimoto H, Ohmomo S, Okamoto T. 2002. Cholesterol removal from media by Lactococci. J Dairy Sci 85: 31823188. doi: 10.3168/jds.S0022-0302(02)74406-8

38. Lan RX, Koo JM, Kim IH. 2016. Effects of Lactobacillus acidophilus supple-mentation in different energy and nutrient density diets on growth performance, nutrient digestibility, blood characteristics, fecal microbiota shedding, and fecal noxious gas emission in weaning pigs. Anim Feed Sci Tech 219: 181-188. doi: 10.1016/j.anifeedsci.2016.06.018

39. Lázaro C. 2005. Efecto de la inclusión de probióticos en el alimento de marranas antes del parto y durante la lactación sobre los parámetros productivos de los lechones lactantes. Tesis de Médico Veterinario. Lima: Univ. Nacional Mayor de San Marcos. 53 p.

40. Ley 576. 2000. Código de Ética para el ejercicio profesional de la medicina veterinaria, la medicina veterinaria y zootecnia y zootecnia. Diario Oficial N. ${ }^{\circ}$ 43.897 de 17 de febrero de 2000 . [Internet]. Disponible en: https:// 
www.mineducacion.gov.co/1621/ articles-105017_archivo_pdf.pdf

41. Liu H, Ji HF, Zhang DY, Wang SX, Wang J, Shan DC, Wang YM. 2015. Effects of Lactobacillus brevis preparation on growth performance, fecal microflora and serum profile in weaned pigs. Livest Sci 178: 251-254. doi: 10.1016/j.livsci.2015.06.002

42. Mandal A, Mandal S, Roy S, Patra A, Pradhan S, Das K, Paul T, et al. 2013. Assessment of efficacy of a potential probiotic strain and its antiuremic and antioxidative activities. e-SPEN J 8: 155163. doi: 10.1016/j.clnme.2013.05.001

43. Manzano C, Estupiñán A, Poveda E. 2012. Efectos clínicos de los probióticos: qué dice la evidencia. Rev Chil Nutr 39: 98-110. doi: 10.4067/S0717-75182012000100010

44. Martinuzzi ALN, Alcántara S, Corbal A, di Leo ME, Guillot A, Palaoro A, et al. 2011. Nitrógeno ureico urinario como indicador del metabolismo proteico en el paciente crítico. Rev Cubana Aliment Nutr 21: 224-235.

45. Martoni C, Bhathena J, Urbanska AM, Prakash S. 2008. Microencapsulated bile salt hydrolase producing Lactobacillus reuteri for oral targeted delivery in the gastrointestinal tract. Appl Microbiol Biot 81: 225-233. doi: 10.1007/ s00253-008-1642-8

46. Matsumoto K, Takada T, Shimizu K, Kado Y, Kawakami K, Makino I, Yamaoka Y, et al. 2006. The effects of a probiotic milk product containing Lactobacillus casei strain Shirota on the defecation frequency and the intestinal microflora of sub-optimal health state volunteers: a randomized placebocontrolled cross-over study. Bioscience Microflora 25: 39-48. doi: 10.12938/ bifidus. 25.39

47. Mosnier E, Etienne M, Ramaekers P, Père MC. 2010. The metabolic status during the peri partum period affects the voluntary feed intake and the metabolism of the lactating multiparous sow. Livest Sci 127: 127-136. doi: 10.1016/j.livsci.2009.06.023
48. Mota-Rojas D, Orozco-Gregorio H, Villanueva-García D, Bonilla-Jaime $H$, Suárez-Bonilla X, HernandezGonzalez R, et al. 2011. Foetal and neonatal energy metabolism in pigs and humans: a review. Vet Med-Czech 56: 215-225.

49. Myers D. 2007. Probiotics. J Exot Pet Med 16: 195-197. doi: 10.1053/ j.jepm.2007.06.008

50. Naqid IA, Owen JP, Maddison BC, Gardner DS, Foster N, Tchórzewska $M A$, et al. 2015. Prebiotic and probiotic agents enhance antibody-based immune responses to Salmonella Typhimurium infection in pigs. Anim Feed Sci Tech 201: 57-65. doi: 10.1016/j.anifeedsci.2014.12.005

51. Nguyen TD, Kang JH, Lee MS. 2007. Characterization of Lactobacillus plantarum $\mathrm{PH} 04$, a potential probiotic bacterium with cholesterol-lowering effects. Food Chem Toxicol 113:358-361. doi: 10.1016/j.jffoodmicro.2006.08.015

52. Nogueira RHG, Guedes RMC, Souza JCA. 2000. Serum concentrations of creatine kinase and of triglycerides during lactation in gilts bred older and in multiparous sows fed ad libitum. Arq Bras Med Vet Zootec 52: 65-67. doi: 10.1590/S0102-09352000000100015

53. Ortiz A, Reuto J, Fajardo E, Sarmiento S, Aguirre A, Arbeláez G, Gómez D, et al. 2007. Evaluación de la capacidad probiótica in vitro de una cepa nativa de Saccharomyces cerevisiae. Univ Scientiarium 13: 138-148.

54. Osorio JH. 2013. Determinación de los niveles de colesterol LDL en una especie con patrón HDL. Rev Inv Vet Perú 24: 277-282. doi: 10.15381/rivep.v24i3.2575

55. Pajarillo EA, Chae JP, Balolong MP, Kim HB, Seo KS, Kang DK. 2015. Characterization of the fecal microbial communities of Duroc pigs using 16S rRNA gene pyrosequencing. Asian Austral J Anim 28: 584-591. doi: 10.5713/ ajas. 14.0651 
56. Park YH, Kim JG, Shin YW, Kim SH, Whang KY. 2007. Effect of dietary inclusion of Lactobacillus acidophilus ATCC 43121 on cholesterol metabolism in rats. J Microbiol Biotechn 17: 655-662.

57. Quemac M. 2014. Evaluación de tres dosis de probiótico (Rhodopseudomonas spp, Lactobacillus spp, Saccharomyces spp) en la alimentación para el engorde de cerdos. Tesis de Ingeniera en Desarrollo Integral Agropecuario. Tulcán, Ecuador: Univ. Politécnica Estatal del Carchi. 62 p.

58. Quiniou N, Richard S, Mourot J, Etienne M. 2008. Effect of dietary fat or starch supply during gestation and/or lactation on the performance of sows, piglets' survival and on the performance of progeny after weaning. Animal 2: 1633-1644. doi: 10.1017/S1751731108002991

59. Ramasamy K, Abdullah N, Wong MC, Karuthan C, Ho YW. 2010. Bile salt deconjugation and cholesterol removal from media by Lactobacillus strains used as probiotics in chickens. J Sci Food Agr 90: 65-69. doi: 10.1002/jsfa.3780

60. Randviir EP, Banks CE. 2013. Chemical analytical methods for quantifying creatinine within biological media. Sensor Actuat B-Chem 183: 239-252.

61. Rao S. 2007. Effects of dietary supplementation of Lactobacillus-based probiotics on growth and gut environment of nursery pigs. MSc Thesis. USA: Texas Tech University. $79 \mathrm{p}$.

62. Rautava S. 2007. Potential uses of probiotics in the neonate. Semin Fetal Neonat M 12: 45-53. doi: 10.1016/ j.siny.2006.10.006

63. Reece W, Ericson H, Goff J, Uemura E. 2015. Dukes' physiology of domestic animals. $13^{\text {th }}$ ed. UK: Wiley-Blackwell. $763 \mathrm{p}$

64. Resta-Lenert S, Barrett K. 2003. Live probiotics protect intestinal epithelial cells from the effects of infection with enteroinvasive. Gut 52: 988-997.
65. Reyes JA, Rodríguez L. 2012. Los probióticos: ¿cómo una mezcla de microorganismos hace un gran trabajo? Rev Mex Cienc Farm 43: 7-17.

66. Rodríguez M. 2009. Aislamiento y selección de cepas del género Lactobacillus con capacidad probiótica e inmunomoduladora. Tesis de Doctorado. Barcelona, España: Univ. Autónoma de Barcelona. $197 \mathrm{p}$.

67. Rodriguez-Diaz R, Caicedo A. 2014. Neural control of the endocrine pancreas. Best Pract Res Cl En 28: 745 756. doi: 10.1016/j.beem.2014.05.002

68. Rondón AJ, Samaniego LM, Bocour $R$, Rodríguez, S, Milián G, Ranilla MJ, Laurencio M, et al. 2008. Aislamiento, identificación y caracterización parcial de las propiedades probióticas de cepas de Lactobacillus sp. procedentes del tracto gastrointestinal de pollos de ceba. Cienc Tecnol Aliment 6: 56-63. doi: 10.1080/ 11358120809487628

69. Ross GR, Gusils C, Oliszewski R, de Holgado SC, González SN. 2010. Effects of probiotic administration in swine. J Biosci Bioeng 109: 545-549. doi: 10.1016/j.jbiosc.2009.11.007

70. Sadrzadeh-Yeganeh H, Elmadfa I, Djazayery A, Jalali J, Heshmat R, Chamary M. 2010. The effects of probiotic and conventional yoghurt on lipid profile in women. Brit J Nutr 103: 1778-1783. doi: 10.1017/ S0007114509993801

71. Sanz Y, Collado MC, Haros M, Dalmau J. 2004. Funciones metabólico-nutritivas de la microbiota intestinal y su modulación a través de la dieta: probióticos y prebióticos. Acta Pediatr Esp 62: 520-526.

72. Schiffl H, Lang SM. 2012. Update on biomarkers of acute kidney injury: moving closer to clinical impact? Mol Diagn Ther 16: 199-207. doi: 10.2165/11634310000000000-00000

73. Semiadi G, Purna RT. 2009. Some notes on biological aspects of captive Javan Warty pig (Sus verrucosus). Biodiversitas 10: 124-128. doi: 10.13057/ biodiv/d100304 
74. Sungsso S, Finocchiaro T. 2010. Handbook of prebiotics and probiotics ingredients. USA: CRC Press. $455 \mathrm{p}$.

75. Vásquez MA, Rondón IS, Eslava PR. 2012. Inmunoestimulantes en teleósteos: probióticos, $\beta$-glucanos y LPS. Orinoquia 16: 46-62.

76. Ventoso B. 2017. Microbiota y metabolismo: la importancia de la microbiota en el correcto funcionamiento fisiológico. España: 3Ciencias. 28 p.

77. Yamano T, Tanida M, Niijima A, Maeda K, Okumura N, Fukushima Y, Nagai K. 2006. Effects of the probiotic strain Lactobacillus johnsonii strain La1 on autonomic nerves and blood glucose in rats. Life Sci 79: 1963-1967. doi: 10.1016/j.lfs.2006.06.038

78. Zhu YH, Li XQ, Zhang W, Zhou D, Liu HY, Wang JF. 2014. Dosedependent effects of Lactobacillus rhamnosus on serum interleukin-17 production and intestinal T-cell responses in pigs challenged with Escherichia coli. Appl Environ Microb 80: 1787-1798. doi: 10.1128/AEM.03668-13 